\title{
Enhancing Scientific Research and Innovation: The role of the Computer Educator
}

\author{
Chukwuma Christian Mgboji, Nnenna Ekpereka Ibezim, Nannim Audu Fadip \\ Department of Computer and Robotics Education \\ University of Nigeria, Nsukka, Enugu State, Nigeria
}

\begin{abstract}
Research is a very important aspect of society as it helps in increasing the stock of knowledge and information through systematic and creative work. Research involves the collection, organization and analysis of data/information to better understand a topic or issue. The process of collection, organization and analysis can be rather cumbersome if the necessary technologies or innovations are not applied. There is need for expertise in these processes. In this descriptive study, 40 Computer Educators were surveyed and their responses showed that computer educators play a prominent role in the pyramid chain of scientific research and innovation. This is further heightened by the global Covid-19 pandemic which has put humans on lockdown and ensured that most activities are carried out virtually or remotely. The relevance of computer literacy is further buttressed as research can become continuous even with the lockdown as long as the necessary skills and expertise are available. The implications of these findings are discussed in the light of available literature.
\end{abstract}

Keywords: Research, Innovation, Computer, Education, Scientific

\section{Introduction}

Research which is as old as man itself has changed the way things are done and improved processes, products and people's way of doing things. Research has carefully shown where we are, in an attempt to highlight where we ought to be. Research is all about addressing an issue or asking a question or solving a life problem [1]. Research is a systematic inquiry to describe, explain, predict, and control an observed phenomenon [2]. It involves inductive and deductive methods and could be by observation, discussion and inference. Research is based on logical reasoning and creates a pathway for generating new questions. Research is naturally analytical in nature and accuracy is one of the most important aspects of research.

Research which could be basic, applied or problem solving could be further grouped under qualitative and quantitative research [3]. Research could also be further broken down based on purpose into exploratory, descriptive and explanatory research. it could make use of different methods which includes focus groups, one on one interview, case study and could be non-scientific or scientific research [4].

Scientific research acquires knowledge and truths about the data or information using techniques that follow the scientific methods such as identification of a problem, formulation of statement of a problem, formulation of hypothesis, data analysis data recording, presentation and interpretation, testing hypothesis and recommendation and conclusion [5]. Chully further stated that scientific research is logical and used for investigating and expanding our understanding. The findings of scientific research can be reproduced and demonstrated to be consistent. Scientific research is a major gateway to innovation as the processes and findings are proven and sustainable.

\section{Literature Review}

Identification of a problem which is the first step in research ensures that the researcher does not embark on a journey of no end. In identifying the problem, it must be established that the problem is researchable and indeed a problem worthy of study [6]. Ratan et al further posited that in academic research for example, the problem must be related to the field of the researcher and must add to the body of knowledge or seek to solve an existing problem. It must be noted that not all problems are researchable and not all problems are for research purposes. When a problem is clearly identified, it gives rise to topic selection.

The selection of a topic is the next step in the research process [7]. Selecting a topic is beyond just writing a long sentence. Topic selection is a major in the research process and follows a pre-defined process such as; the topic must not exceed a certain number of words, the number of conjunctions used must be minimal, the topic must convey the thoughts and expectation of the researcher, the topic must be simple and easy to understand and above all the topic must not be ambiguous. When a topic is properly selected, the correct research methodology is needed to achieve the desired aim of the study.

Research methodology is the specific procedures or techniques used to identify, select, process, and analyse information about a topic [8]. LibGuides 
further stated that in a research paper, the methodology section allows the reader to critically evaluate a study's overall validity and reliability. The methodology section seeks answers to two main questions; How was the data collected and how was it analysed? Research methodology is the path through which researchers conduct their research and it shows the path through which these researchers formulate their problem and objective and present their result from the data obtained during the study period [9]. Research methodology ultimately outlines how data will be collected and details into the next step of data collection.

Data collection and analysis is a major phase in the research process and must be handled with sincerity and diligence. Data collection could be primary or secondary [10]. The primary data refers to data collected by the researcher, but the secondary data refers to data that was collected by someone other than the researcher. The primary sources could be field observation, interview, and informal discussions, survey questionnaires and interview questions. The secondary source includes literature/desk review and industry documents and reports. Data analysis is the process of evaluating data using the logical and analytical reasoning to carefully examine each component of the data collected or provided [11]. Maintaining the integrity of the data is crucial for a data analyst to procure accurate and appropriate analysis. A credible data analyst should have the skills to analyse the statistics of the data and turn the data into actionable insights. Improper analysis always distorts the scientific findings and lead the readers to believe in a wrong notion. The data analysis stage is closely followed by the reporting and dissemination of research findings.

Reporting and dissemination of research finding is also a very vital phase of research. If the finding is not well documented or presented, it would lead to wrong information with no action but when the findings are well reported and disseminated, it could lead to innovations and improvement of the entire process [12]. For any research work to bring about the desired change, it must be well presented, and the activities properly tested to ascertain that it will bring the desired change or innovation. Every research must be geared towards changing the usual and improving the existing in line with current and cutting-edge advancement and innovations.

Innovation which is a product of scientific research [13] is the conversion of decisions and ideas into a workable solution [14]. Innovation deals more with a revolutionary new product or service than an evolutionary one, such as a line extension or an improvement to an existing item. Often an innovation has the potential to disrupt a trend or normal situation by changing the status quo and replacing what already exists with something totally unique [15]. Innovation in summary is a product of research and development (RandD) which is a product of Education.

Education is the change of behaviour through information exchange and knowledge development which could be formal or informal. Education seeks to ensure that humans are able to compete favourable in a developing world where nothing is static [16]. Education is broken into stages such as primary, secondary and tertiary. There is also the pre-primary which includes the crèche and the nursery. Education is a mix of theory, practical and research to ensure that the individual is thoroughly equipped in this changing world. Furthermore, education is classified into various disciplines which must implement the core theories, practical and research as it applies to their curriculum. Some of the disciplines available include Accountancy, Medicine, Law, Computer science, pharmacy, Engineering and Computer Education [17].

Computer Education is a discipline that combines the science curriculum and the education curriculum [18]. Computer Education seeks to improve the way things are done by developing individuals who can properly make use of the computer in carrying out their task which could be theoretical, practical or research based while also helping others do so. The computer educator is saddled with the responsibility of ensuring that these tasks are done in an easier manner and also the outcome not compromised in anyway [19]. Aforetime, these processes were manual and wasted a lot of time as the Library and Librarians were the major source of information. We depended on libraries and librarians. Researchers would spend hours in a section of a good academic library, going from book to book and taking copious notes on paper, of course [20].

Therefore, this study investigates the role of the computer educator in the selection of researchable topic, the role of the computer educator in the choice of research methodology, the role of the computer educator in data collection and analysis and the role of the computer educator in the reporting and dissemination of research findings and how these finding have impacted on innovation.

\section{Method}

The study adopted the descriptive survey. A descriptive survey is a procedure in which a quantitative researcher administers a survey to a sample or entire population to establish the range and distribution of some social characteristics, like education or training, occupation, and location, and to find out how these characteristics may be related to certain behaviour patterns or attitudes [21]. The population of the study is made up of 50 Computer Educators drawn from lecturers and researchers on which the online questionnaire was administered to. The instrument used for data collection was face 
validated by three experts. The 20 items online questionnaire was developed using Google form to investigate the role of the Computer Educator in scientific research and innovation. The online questionnaire was distributed to respondents via emails, Facebook and WhatsApp platforms. The return rate was $80 \%$ as only 40 of the Computer Educators responded to the online questionnaire. The data was analysed using means and standard deviations, The Statistical Package for Social Sciences (SPSS) was used in analysing the data.

\section{Results}

What is the role of Computer Educators in the selection of research topic?

Table 1. Mean ratings and standard deviation of responses on the role of computer educators in the selection of research topics. $\mathrm{N}=40$

\begin{tabular}{c|lllll} 
S/N & Item Statement & Mean & SD & Remark \\
\hline 1 & $\begin{array}{l}\text { Ensure research topic length agrees with prescribed } \\
\text { standards. }\end{array}$ & 3.40 & 0.63 & Needed \\
2 & Ensure research topic is not plagiarized. & 3.70 & 0.67 & Needed \\
3 & Ensure research topic is researchable & 3.80 & 0.69 & Needed \\
4 & Ensure research topic is new and not already flooded & 3.50 & 0.65 & Needed \\
5 & Provide tools that aid research topic selection. & 3.60 & 0.66 & Needed
\end{tabular}

Data available on Table 1 shows that all the items had their means ranging from 3.40 to 3.80 . The mean value range is greater than the criterion mean value of $2.50(>2.50)$ thus indicating that all the items are roles of computer educators in the choice of research topic. The standard deviation of all the items ranged from
0.63 to 0.69 which indicates that the respondents were not far from the mean and from one another in responses.

What is the role of Computer Educators in the choice of a research methodology?

Table 2. Mean ratings and standard deviation of responses on the role of Computer Educators in the choice of research methodology. $\mathrm{N}=40$

\begin{tabular}{c|llll} 
S/N & Item Statement & Mean & SD & Remark \\
\hline 1 & Identifies who the respondents will be. & 3.21 & 0.60 & Needed \\
2 & Identifies how data integrity can be enforced & 3.35 & 0.64 & Needed \\
3 & Identifies easy collection of data. & 3.50 & 0.62 & Needed \\
4 & Identifies easy collation of data. & 3.70 & 0.65 & Needed \\
5 & Identifies how data will be analysed easily & 3.60 & 0.64 & Needed
\end{tabular}

Data available on Table 2 shows that all the items had their means ranging from 3.21 to 3.70 . The mean value range is greater than the criterion mean value of 2.50 (> 2.50) thus indicating that all the items are roles of computer educators in the choice of an appropriate research methodology. The standard deviation of all the items ranged from 0.60 to 0.65 which indicates that the respondents were not far from the mean and from one another in responses.

Table 3. Mean ratings and standard deviation of responses on the role of Computer Educators in data collection and data analysis. $\mathrm{N}=40$

\begin{tabular}{c|llll} 
S/N & Item Statement & Mean & SD & Remark \\
\hline 1 & Design of research instrument & 3.21 & 0.53 & Needed \\
2 & Development of research instrument using google form & 3.45 & 0.58 & Needed \\
3 & Collation of responses using google form & 3.35 & 0.55 & Needed \\
4 & Analysis of result & 3.53 & 0.61 & Needed \\
5 & Interpretation of research responses. & 3.48 & 0.60 & Needed
\end{tabular}

Data available on Table 3 shows that all the items had their means ranging from 3.21 to 3.53 . The mean value range is greater than the criterion mean value of 2.50 (> 2.50) thus indicating that all the items are roles of computer educators in data collection and analysis.
The standard deviation of all the items ranged from 0.53 to 0.61 which indicates that the respondents were not far from the mean and from one another in responses. 
Table 4. Mean ratings and standard deviation of responses on the role of Computer Educators in reporting and dissemination of Research findings. $\mathrm{N}=40$

\begin{tabular}{|c|c|c|c|c|}
\hline $\mathrm{S} / \mathrm{N}$ & Item Statement & Mean & SD & Remark \\
\hline 1 & Presentation of Results in approved format & 2.90 & 0.50 & Needed \\
\hline 2 & $\begin{array}{l}\text { Presentation of research findings in-line with reviewed } \\
\text { literature. }\end{array}$ & 3.00 & 0.58 & Needed \\
\hline 3 & Presentation of Conclusion and Recommendation & 3.20 & 0.55 & Needed \\
\hline 4 & Easy collation of References using ICT tools. & 3.90 & 0.79 & Needed \\
\hline 5 & Presentation of References in approved format & 3.70 & 0.60 & Needed \\
\hline
\end{tabular}

Data available on Table 4 shows that all the items had their means ranging from 2.90 to 3.90 . The mean value range is greater than the criterion mean value of $2.50(>2.50)$ thus indicating that all the items are roles of computer educators in reporting and dissemination of research finding. The standard deviation of all the items ranged from 0.50 to 0.79 which indicates that the respondents were not far from the mean and from one another in responses.

\section{Discussion}

The impact of technology on different facets of society especially Education has been enormous, and the place of the Computer Educator has become very imminent going by the technological skills he possesses and his expertise in improving processes and driving innovation [22]. A useful application of the expertise of the Computer Educator is in Research. Findings of the study revealed that the Computer Educator plays a major role in ensuring that research topic length agrees with prescribed standards, ensuring that research topic is not plagiarized, ensuring that research topic is researchable, ensuring research topic is new and not already flooded, and provide tools that aid research topic selection and so on. These findings strongly agree with Ratan et al. [6]. This study also found out that the Computer Educator identifies the following in the choice of an appropriate methodology for the research, who the respondents will be, how data integrity can be enforced, easy collection of data, easy collation of data and how data will be analysed easily. This agrees with Libguides [8], and Snyder [23] who asserted that the methodology has tremendous impact on the respondents and helps to identify, select, process, and analyse information about a topic. Other findings of the study showed that the computer educator plays a significant role in the data collection process of research through the design of research instrument, development of research instrument using google form, collation of responses using google form, analysis of result and interpretation of research responses. Further findings revealed that the Computer Educator is also actively involved in the reporting and dissemination of research finding through presentation of results in approved format, presentation of research findings in-line with reviewed literature, presentation of conclusion and recommendation, easy collation of references using ICT tools and the presentation of references in approved format. These findings agree with RossHellauer et al. [24] who posited that the reporting and dissemination of research findings and proper collation of references are evidence of proper research. It also agrees with Derman et al. [12] that when findings are not properly documented it will lead to no action.

\section{Recommendations}

Based on the findings of this study, the study recommends:

- The Computer Educator should be fully involved in the entire research process and his activities properly incorporated into the various departments and research areas. The Computer Educator should in turn ensure proper training and retraining of researcher in line with present day research models especially in the post-covid era.

- The role of the computer Educator should be well defined to avoid ambiguity and unnecessary clash of interest in the course of discharging of duties.

\section{Conclusions}

Computer Educators due to their educational background and experience are a vital agent for the improvement of research and innovation. The era of manual research is gradually fizzling away and there is need for an enhancement to meet up with the current challenges especially with the outbreak of the pandemic and the need to maintain social distancing and observe lockdown. The Computer Educator does not only educate the users but also uses the available technologies in the entire research process from choice of research topic to the documentation and presentation of research findings. The presentation of these findings is critical to the study as it ensures that necessary actions are taken which will birth the needed innovations. 


\section{References}

[1] Saunders, M., Lewis, P. and Thornhill, A. (2009). Understanding research philosophies and approaches. Research Methods for Business Students. 4. 106-135.

[2] Questionpro. (2018). What is Research- Definition, Types, Methods and Examples. https://www.questionpro.co m/blog/what-is-research/. (Access Date: 10 October 2021).

[3] Daniel, E. (2016). The Usefulness of Qualitative and Quantitative Approaches and Methods in Researching Problem-Solving Ability in Science Education Curriculum. Journal of Education and Practice, 7(15), 91-100. DOI: /2222-288X.

[4] De Carlo, M. (2018). 7.1 Types of research. Open Social Work Education. https://scientificinquiryinsocialwork.press books.com/chapter/7-1-types-of-research/. (Access Date: 10 October 2021).

[5] Chully, M., D. (2020). Distinguish or difference between scientific research and nonscientific research. http://chullyt zed.blogspot.com/2017/03/distinguish-or-different-betwee n.html. (Access Date: 10 October 2021).

[6] Ratan, S. K., Anand, T., and Ratan, J. (2019) Formulation of Research Question - Stepwise Approach Journal of Indian Association of Pediatric Surgeons, 24(1), 15-20. DOI: 10.4103/jiaps.JIAPS_76_18.

[7] Nwakpa, P. P. (2015). Research in Tertiary Institutions in Nigeria: Issues, Challenges And Prospects: Implication for Educational Managers. 20(6), 45-49. DOI: 10.979 0/0837-20614549.

[8] LibGuides (2020): Organizing Your Social Sciences Research Paper. The Methodology. https://libguides.usc .edu/writingguide/methodology. (Access Date: 13 November 2021).

[9] Kassu Jilcha Sileyew (2019). Research Design and Methodology, Cyberspace, Evon Abu-Taieh, Abdelkrim El Mouatasim and Issam H. Al Hadid, IntechOpen, DOI: 10.5772/intechopen.85731.

[10] CYFAR. (2020). Data Sources. https://cyfar.org/datasources. (Access Date: 16 October 2021).

[11] Perez, E. (2020). What is Data Analysis and Its Methods? | Utreee. https://www.utreee.com/what-is-dataanalysis-and-its-methods\%EF\%BB\%BF/. (Access Date: 10 October 2021).

[12] Derman, R.J., Jaeger, F.J. (2018). Overcoming challenges to dissemination and implementation of research findings in under-resourced countries. Reprod Health 15, 86. DOI: $10.1186 / \mathrm{s} 12978-018-0538-\mathrm{z}$

[13] Hauser, J., Tellis, G. and Griffin, A. (2006). Research on Innovation: A Review and Agenda for Marketing Science. Marketing Science. 25. 10.1287/mksc.1050.0144.

[14] Llopis, G. (2013). The 12 things that successfully convert great ideas into a reality. https://www.forbes.co $\mathrm{m} /$ sites/glennllopis/2013/04/01/12-things-successfully-con vert-a-great-idea-into-a-reality/?sh=22ee41164e86. (Acces s Date: 10 October 2021).
[15] SIS International. (2020). Innovation Research and Strategy. https://www.sisinternational.com/solutions/innov ation/innovation-research/. (Access Date: 10 October 2021).

[16] Linda D., Lisa Flook, C. C., Brigid, B. and David O., (2020) Implications for educational practice of the science of learning and development, Applied Developmental Science, 24:2, 97-140. DOI: 10.1080/10888691.2018.153 7791

[17] Dambo, T. (2020). Department of Curriculum Studies and Educational Technology. https://www.uniport.edu.ng/ schools/education/2019-01-24-10-46-38.html. (Access Da te: 13 November 2021).

[18] School Working Group (2020). Computer Science: A curriculum for schools. https://www.computingatschool.or g.uk/data. (Access Date: 13 November 2021).

[19] Technology in Education - School. (2020). https://edu cation.stateuniversity.com/pages/2495/Technology-in-Edu cation-SCHOOL.html. (Access Date: 13 November 2021).

[20] Grant, C., and Grinberg, D. (2019). How did researchers find articles before the Internet and the computer era? https://academia.stackexchange.com/quest ions/132376/how-did-researchers-find-articles-before-theinternet-and-the-computer-era/132377. (Access Date: 16 November 2021).

[21] Creswell, J.W., (2012). Educational research: planning, conducting, evaluating quantitative and qualitative research (4th ed.). Boston. Pearson education inc.

[22] Urhahne, Schanze, Bell, Mansfield and Holmes. (2010). Role of the Teacher in Computer-supported Collaborative Inquiry Learning, International Journal of Science Education, 32:2, 221-243, DOI: 10.1080/0950069 0802516967.

[23] Snyder, H., (2019). Literature review as a research methodology: An overview and guidelines. Journal of Business Research, 104(1), 333-339. DOI: 10.1016/j.jbu sres.2019.07.039.

[24] Ross-Hellauer T, Tennant JP, Banelytė V, Gorogh E, Luzi D, et al. (2020) Ten simple rules for innovative dissemination of research. PLOS Computational Biology 16(4): e1007704. DOI: 10.1371/journal.pcbi.1007704. 